Article

\title{
Replacement of Chromium by Non-Toxic Metals in Lewis-Acid MOFs: Assessment of Stability as Glucose Conversion Catalysts
}

\author{
Ralentri Pertiwi ${ }^{1,2,3, \dagger}$, Ryan Oozeerally ${ }^{1,+}$, David L. Burnett ${ }^{2}$, Thomas W. Chamberlain ${ }^{1,2}$, \\ Nikolay Cherkasov ${ }^{1}{ }^{1}$, Marc Walker ${ }^{4}$, Reza J. Kashtiban ${ }^{4}$, Yuni K. Krisnandi ${ }^{3}$, \\ Volkan Degirmenci ${ }^{1, * \mathbb{D}}$ and Richard I. Walton ${ }^{2, *(D)}$ \\ 1 School of Engineering, University of Warwick, Coventry CV4 7AL, UK; ralentri.pertiwi@gmail.com (R.P.); \\ R.Oozeerally@warwick.ac.uk (R.O.); T.W.Chamberlain@warwick.ac.uk (T.W.C.); \\ N.Cherkasov@warwick.ac.uk (N.C.) \\ 2 Department of Chemistry, University of Warwick, Coventry CV4 7AL, UK; D.Burnett.1@warwick.ac.uk \\ 3 Department of Chemistry, Universitas Indonesia, Depok 16424, Indonesia; yuni.krisnandi@sci.ui.ac.id \\ 4 Department of Physics, University of Warwick, Coventry, CV4 7AL, UK; M.Walker@warwick.ac.uk (M.W.); \\ R.Jalilikashtiban@warwick.ac.uk (R.J.K.) \\ * Correspondence: V.Degirmenci@warwick.ac.uk (V.D.); R.I.Walton@warwick.ac.uk (R.I.W.) \\ + These authors contributed equally to the work.
}

Received: 16 April 2019; Accepted: 6 May 2019; Published: 9 May 2019

\begin{abstract}
The metal-organic framework MIL-101(Cr) is known as a solid-acid catalyst for the solution conversion of biomass-derived glucose to 5-hydroxymethyl furfural (5-HMF). We study the substitution of $\mathrm{Cr}^{3+}$ by $\mathrm{Fe}^{3+}$ and $\mathrm{Sc}^{3+}$ in the MIL-101 structure in order to prepare more environmentally benign catalysts. MIL-101(Fe) can be prepared, and the inclusion of Sc is possible at low levels (10\% of Fe replaced). On extended synthesis times the polymorphic MIL-88B structure instead forms.Increasing the amount of Sc also only yields MIL-88B, even at short crystallisation times. The MIL-88B structure is unstable under hydrothermal conditions, but in dimethylsulfoxide solvent, it provides 5-HMF from glucose as the major product. The optimum material is a bimetallic $(\mathrm{Fe}, \mathrm{Sc})$ form of MIL-88B, which provides $\sim 70 \%$ conversion of glucose with $35 \%$ selectivity towards 5 -HMF after 3 hours at $140{ }^{\circ} \mathrm{C}$ : this offers high conversion compared to other heterogeneous catalysts reported in the same solvent.
\end{abstract}

Keywords: Metal-organic framework; Lewis acid; fructose; 5-hydroxymethyl furfural; biomass

\section{Introduction}

Biomass-derived glucose has received considerable attention as a potential feedstock for the production of useful organic molecules. One attractive target of glucose conversion is the molecule 5-hydroxymethyl furfural (5-HMF): this is regarded as a platform molecule that can be used as a precursor for an extensive range of plastics, polymers, and fuels [1-4]. Acid catalysts are needed to bring about the transformation of glucose, via fructose, into 5-HMF, and both Lewis and Brønsted acids have been implicated in the transformation mechanism [5-8]. Figure 1 shows the most common reaction pathways that have been proposed in the literature $[9,10]$. It is well established that the isomerisation of glucose to fructose requires a Lewis acid catalyst, and mannose can be produced as an alternative product, while the dehydration of fructose to 5-HMF is catalysed by Brønsted acids that may also result in the further transformation (hydrolysis) to levulinic acid and formic acid [10]. Humins are insoluble carbon-rich materials that are commonly formed as a side-product, and other 
small molecules may be possible as intermediates and byproducts, depending on the choice of catalyst and solvent [2].

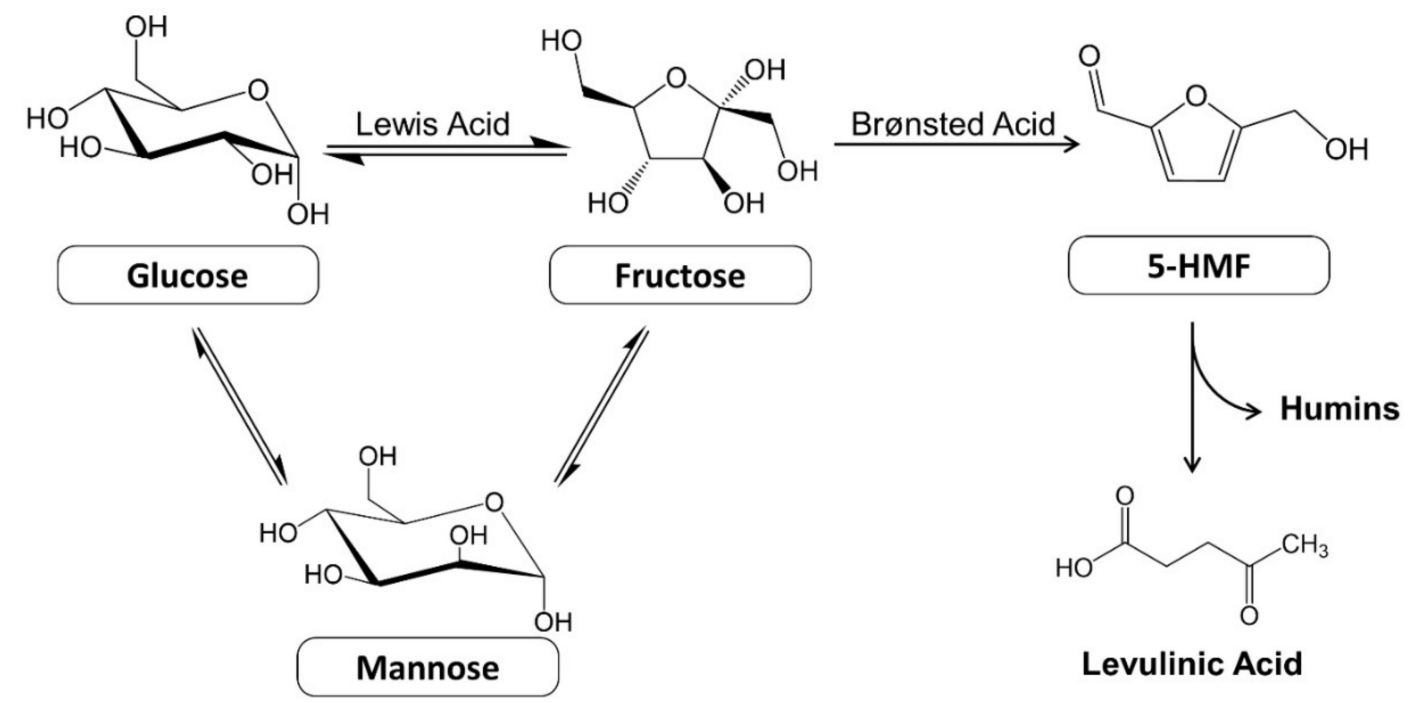

Figure 1. Pathway for the conversion of glucose to 5-HMF, showing possible byproducts, as described in the literature $[9,10]$. Glucose and mannose are shown in their $\alpha$-pyranose forms and fructose in its $\alpha$-furanose form.

Heterogeneous catalysts are desirable for the conversion of glucose, and Davis and co-workers pioneered the use of zeolite-based catalysts that contain both Lewis and Brønsted acid sites; in particular, tin-substituted zeolite beta (Sn-beta) has been shown as an effective catalyst for the isomerisation of glucose into fructose and mannose in water [9], or the direct formation of 5-HMF from glucose when a biphasic water/tetrahydrofuran reactor system was used [11]. The stability of the heterogeneous catalyst in the reaction medium is a major challenge in the conversion of glucose [12]. Although Sn-beta is hydrothermally stable at low $\mathrm{pH}$ and the solid can be recycled, a significant disadvantage in its use, particularly on an industrial scale, is that the synthesis of the catalyst is a lengthy process requiring a 40 day hydrothermal reaction, and furthermore requires hydrofluoric acid, an extremely toxic and corrosive substance [9]. A challenge is to identify new solution-stable solid-acid catalysts that provide glucose conversion with selectivity towards fructose and 5-HMF; the catalysts must also be easy to prepare, using environmentally benign reagents and processes. In recent years, porous metal-organic frameworks (MOFs) have been studied for wide-ranging applications [13], such as adsorbents [14], gas storage and separation [15], and heterogeneous catalysts [16-20]. MOF materials have many attractive features for catalysis, such as large surface areas and pore sizes, as well as controllable properties, since the wide choice of ligands and metals provides a large variety of structures, porosities, and chemical functionalities. The scope for adding extra functionality, for example, by post-synthesis modification of the organic ligands, offers the possibility of multifunctional heterogeneous catalysts that contain more than one active site for tandem or multi-step conversions [21].

Brønsted acid functionality in MOFs has been introduced in a number of ways [22], but particularly useful is the addition of sulfonic acid $\left(-\mathrm{SO}_{3} \mathrm{H}\right)$ functionalities to the organic ligands, such as by their addition to aromatic polycarboxylate linkers that make up many common MOF structures [23,24]. Lewis acidity may be present in MOF structures in the form of coordinatively unsaturated metal sites, such as metals associated with loosely bound solvent, in addition to the coordinating atoms of the ligands making up the framework [25]. The dehydration of glucose to 5-HMF using MIL-101(Cr) functionalised with sulfonic acid groups was reported by Herbst and Janiak in 2016 [10]. The highest 5-HMF yield (29\%) was obtained at $403 \mathrm{~K}$ with a 5 hour reaction time in a THF:water (39:1 v:v) solvent. Su et al. studied the same catalyst and found the highest conversions were possible in mixed organic:aqueous solvents, and demonstrated the effectiveness of the solid in a fixed-bed continuous 
reactor [26]. MIL-101(Cr), UiO-66, and MIL-53(Al) functionalised with sulfonic acid groups have also been studied as catalysts for glucose conversion, and MIL-101(Cr)- $\mathrm{SO}_{3} \mathrm{H}$ showed high efficiency, with more than 90\% yield of 5-HMF from fructose when dimethyl sulfoxide (DMSO) was used as solvent [27]. Previously, MIL-101(Cr) had been used as a host for phosphotungstic acid, thereby adding Brønsted acidity for carbohydrate dehydration [28], while most recently, Guo et al. found that a composite of MIL-101(Cr) and chromium hydroxide gave superior isomerisation of glucose to fructose in ethanol solvent via ethyl fructoside that required hydrolysis in a second step [29]. Other MOFs that have been used for glucose conversion include the zirconium-based NU-1000, with phosphate modification to induce Lewis acidity [30], and the zirconium material UiO-66 with sulfo-modified ligands and inherent Lewis acidity from defects notably allowing conversion of glucose to fructose, along with a significant amount of 5-HMF in water alone [31], and selective conversion of glucose to fructose with iso-propanol solvent [32]. Sulfonated UiO-66 has been further tuned to optimise activity towards glucose conversion [33], compared with other zirconium MOFs [34], and has also been used to effect the esterification of levulinic acid with ethanol [35].

Based on the efficiency of MIL-101(Cr) as a catalyst for glucose conversion, we have now investigated the modification of this material by substitution of the metals making up the structure. MIL-101 is constructed from the cheap and benign ligand benzene-1,4-dicarboxylate (BDC), but can be prepared with various other trivalent cations [36]. The metal $\mathrm{Cr}$ is known to be toxic to humans and harmful to the environment, and although these detrimental properties are largely associated with the +6 oxidation state, which is established to be carcinogenic, $\mathrm{Cr}^{3+}$ is considered an irritant, with evidence also for it being an allergen [37]; therefore its release into the environment is clearly undesirable, where it might encounter oxidising conditions. Herein, we report a study of variants of MIL-101 using Fe and Sc as replacements for $\mathrm{Cr}$ and their potential as catalysts for glucose conversion. Homogeneous scandium triflate is a powerful Lewis acid catalyst [38], and the synthesis of a range of porous scandium carboxylate MOFs with structures analogous to MIL-88B, MIL-100, and MIL-53 was described previously [39], with MIL-100 (Sc) proven to be an effective Lewis-acid catalyst [40]. Mixed-metal MIL-100 (Sc,Fe) materials have been used as dual acid-redox catalysts [41]. Figure 2 shows the structures of two of the MOFs that are relevant to the current work: MIL-101 and MIL-88B. Both are constructed from the same trimeric building unit, consisting of three octahedrally coordinated metal centres with a common shared oxide, and linked by benzene-1,4-dicarboxylate (BDC), but the connectivity gives different structures [42]. Each octahedral metal centre contains a bound solvent molecule, as indicated by the terminal atom on Figure 2a, which may provide a Lewis acid site. 

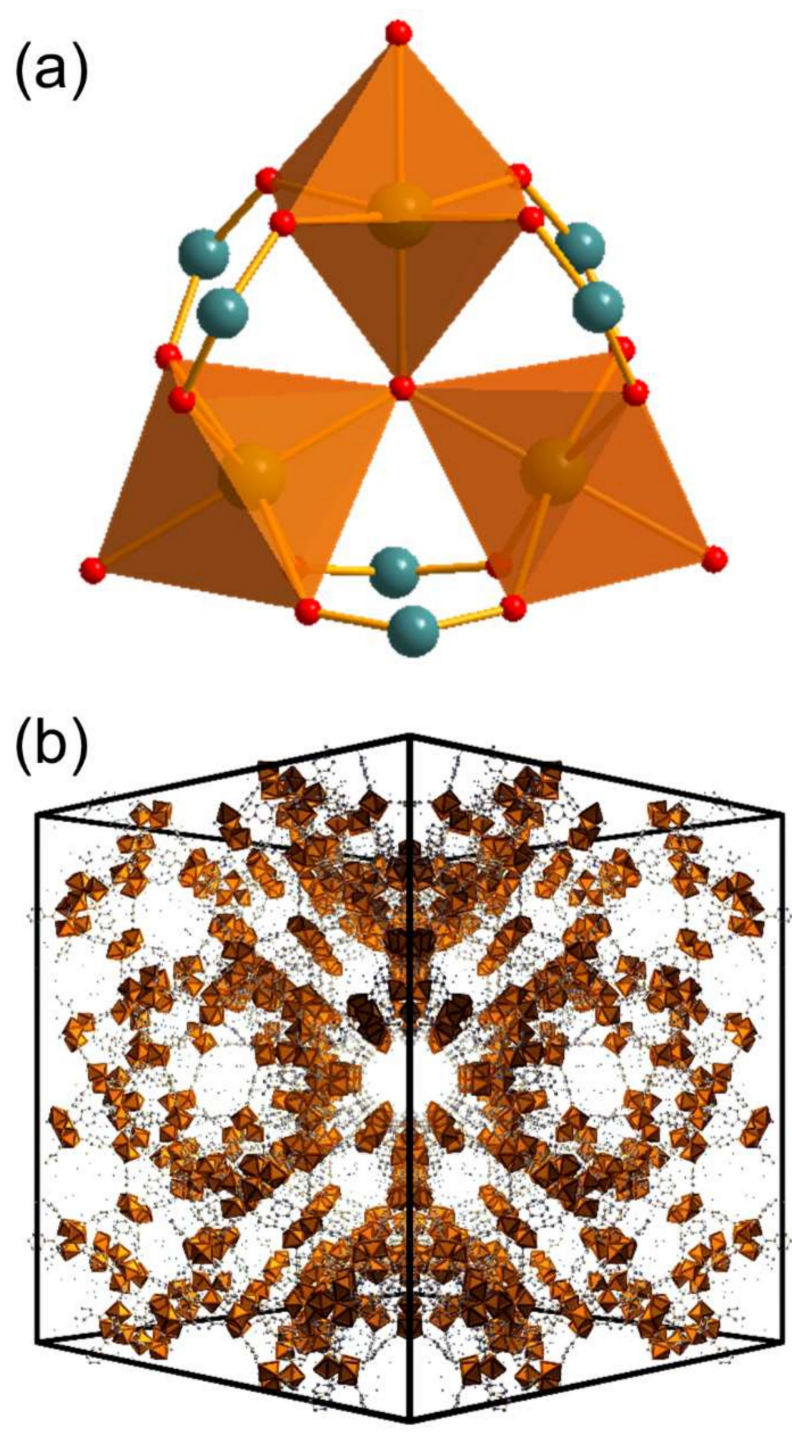

(c)

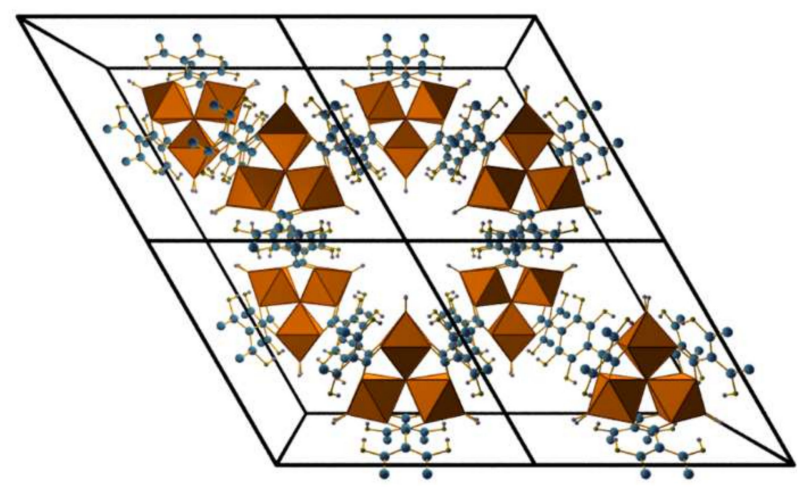

Figure 2. The structures of the MOFs investigated in this work: (a) the trimeric building unit showing three $\left\{\mathrm{FeO}_{6}\right\}$ octahedral units linked by a common oxygen atom, (b) the cubic unit cell of MIL-101, and (c) four unit cells of hexagonal MIL-88B. Carbon atoms of the benzene-1,4-dicarboxylate (BDC) linker are shown as grey spheres. 


\section{Results}

MIL-101(Fe) was obtained by a solvothermal method from benzene-1,4-dicarboxylic acid and iron (III) chloride, according to the method of Zhu et al. [43] The powder X-ray diffraction (PXRD) pattern of the material prepared at 3 hours reaction time confirms the identity of the material by comparison with the simulated pattern from the literature (Figure 3). The differences in relative intensity between the low angle peaks (at less than $6^{\circ} 2 \theta$ ) and those at higher angle (greater than $8^{\circ} 2 \theta$ ) in the measured pattern compared to the simulated pattern is accounted for by the presence of solvent in the as-prepared sample; in contrast, the simulated pattern is for an idealised guest-free framework. These X-ray powder patterns are typical of MIL-101 samples reported in the literature [44-46]. There is also evidence in the PXRD for the presence of an impurity phase in the sample, which we identify below as being MIL-88B (Figure 1) [47]. It is already known that MIL-88B and MIL-101 are "framework isomers" and may form in competition to each other $[4,48,49]$.

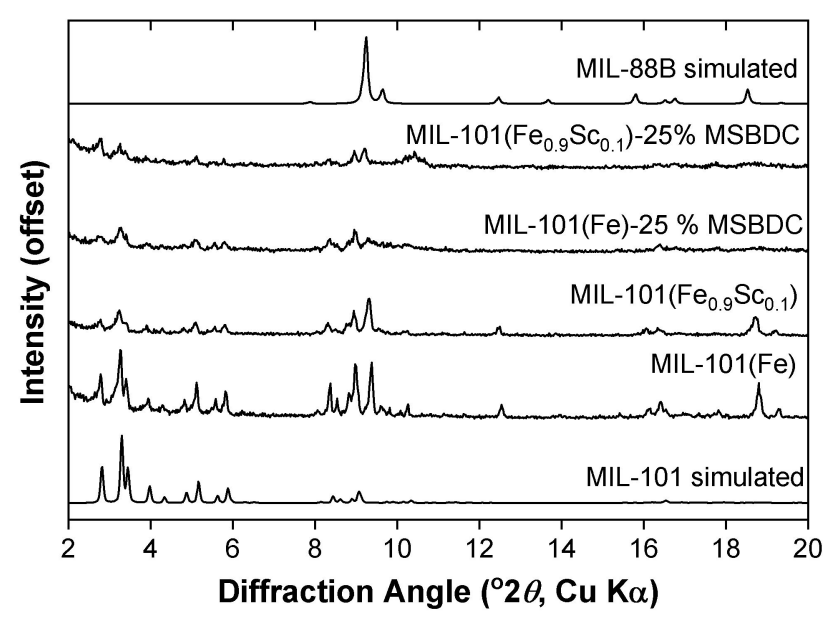

Figure 3. Powder X-ray diffraction patterns of samples of MIL-101 prepared by solvothermal synthesis at 3 hour reaction times. The simulated pattern of MIL-101 was produced from the published structure of Férey et al. [36] and that of MIL-88B from the refined diffraction profile in this work for MIL-88B(Fe).

Figure 3 also shows PXRD patterns of materials prepared where small amounts of $\mathrm{Sc}^{3+}$ are used to replace some of the $\mathrm{Fe}^{3+}$, or some of the BDC linker is replaced by mono-2-sulfobenzene-1,4-dicarboxylate (MSBDC). In both cases, the crystallinity of the resultant product is considerably less than for the Fe material, and the MIL-88B impurity remains in the samples. SEM was used to detect the presence of the sulfo-modified ligand in the material, but no signal from sulfur was observed. Since we used this method successfully to image sulfur in sulfo-modified UiO-66 [31], we conclude that for MIL-101(Fe) prepared by this method, the incorporation of the sulfo-modified ligand is negligible. Fourier transform infrared (FT-IR) spectra also provided no evidence for any characteristic sulfo bands. Owing to the lack of any sulfo-functionalisation, we excluded these samples from any further study.

The highest scandium amount that can be introduced to MIL-101(Fe) is only $10 \%$. If $50 \%$ of the Fe is replaced by Sc (note that this is the nominal metals ratio used in the synthesis) then the material formed is solely MIL-88B under the synthesis conditions that we have used, labelled MIL-88B(Fe $\left.{ }_{0.5} \mathrm{Sc}_{0.5}\right)$, and indeed if longer synthesis times are used then, even for the iron material, only MIL-88B is found (see Figure 4). The powder X-ray pattern of MIL-88B matches that reported by Ma et al. who prepared the iron form by microwave synthesis in the same solvent [50]. Figure 4 also demonstrates the stability of MIL-88B in DMSO upon prolonged heating: although the powder pattern shows some broadening of the peaks, the material clearly has the same structure. The materials are, however, unstable in water: upon heating to $140{ }^{\circ} \mathrm{C}$ for 3 hours, the MOF structure collapses and the only crystalline 
product recovered is the acid of the BDC linker, along with an orange powder, presumably amorphous iron oxide.

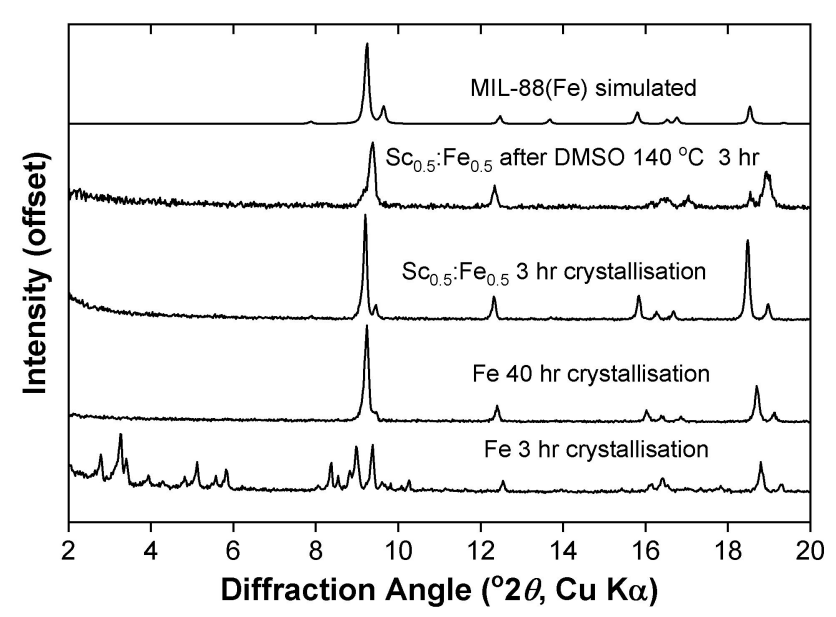

Figure 4. Powder X-ray diffraction patterns of MOFs transformation from MIL-101(Fe), 3 hour crystallisation) to MIL- $88 \mathrm{~B}(\mathrm{Fe}), 40$ hour crystallisation, along with mixed (Fe,Sc) (nominal metals ratio 1:1), 3 hour crystallisation. The second from top pattern illustrates the stability of the mixed-metal phase on heating in DMSO.

Confirmation of the identity of the more stable MOF structure in the synthetic conditions used was provided by a more detailed analysis of higher resolution powder X-ray diffraction patterns, and Figure 5 shows the profile fits to the MIL- $88 \mathrm{~B}(\mathrm{Fe}), \mathrm{MIL}-88 \mathrm{~B}\left(\mathrm{Sc}_{0.5} \mathrm{Fe}_{0.5}\right)$ and MIL- $88 \mathrm{~B}(\mathrm{Sc})$ materials. The refined lattice parameters (Figure 5) fitted using the hexagonal space-group $P \overline{6} 2 c$ are consistent with those reported in the literature for MIL-88B materials: for example, Ma et al. found $a \sim 12.7 \AA$, $c \sim 18.4 \AA$ and $V \sim 2570.2 \AA^{3}$ for MIL-88B(Fe) isolated from $N, N$-dimethylformamide (DMF) [50], and Mowat et al. found $a=11.2190 \AA, c=19.373 \AA, V=2112.27 \AA^{3}$ for MIL-88B(Sc) containing a mixture of water and DMF [39]. MIL-88B, however, is an example of a breathing MOF and the lattice parameters can vary dramatically with the amount, or type, of solvent present [51], so it is difficult to draw conclusions in the trends in the values of the fitted lattice parameters for the three materials that we have studied. Larger unit cell volumes are observed for both the Sc-containing samples we have prepared compared to the iron form, which is consistent with the larger ionic radius of octahedral $\mathrm{Sc}^{3+}$ compared to $\mathrm{Fe}^{3+}$ [52]. However, the presence of different amounts of solvents (or mixtures of water and DMF) cannot be ruled out, which may also adjust the unit cell volume. 


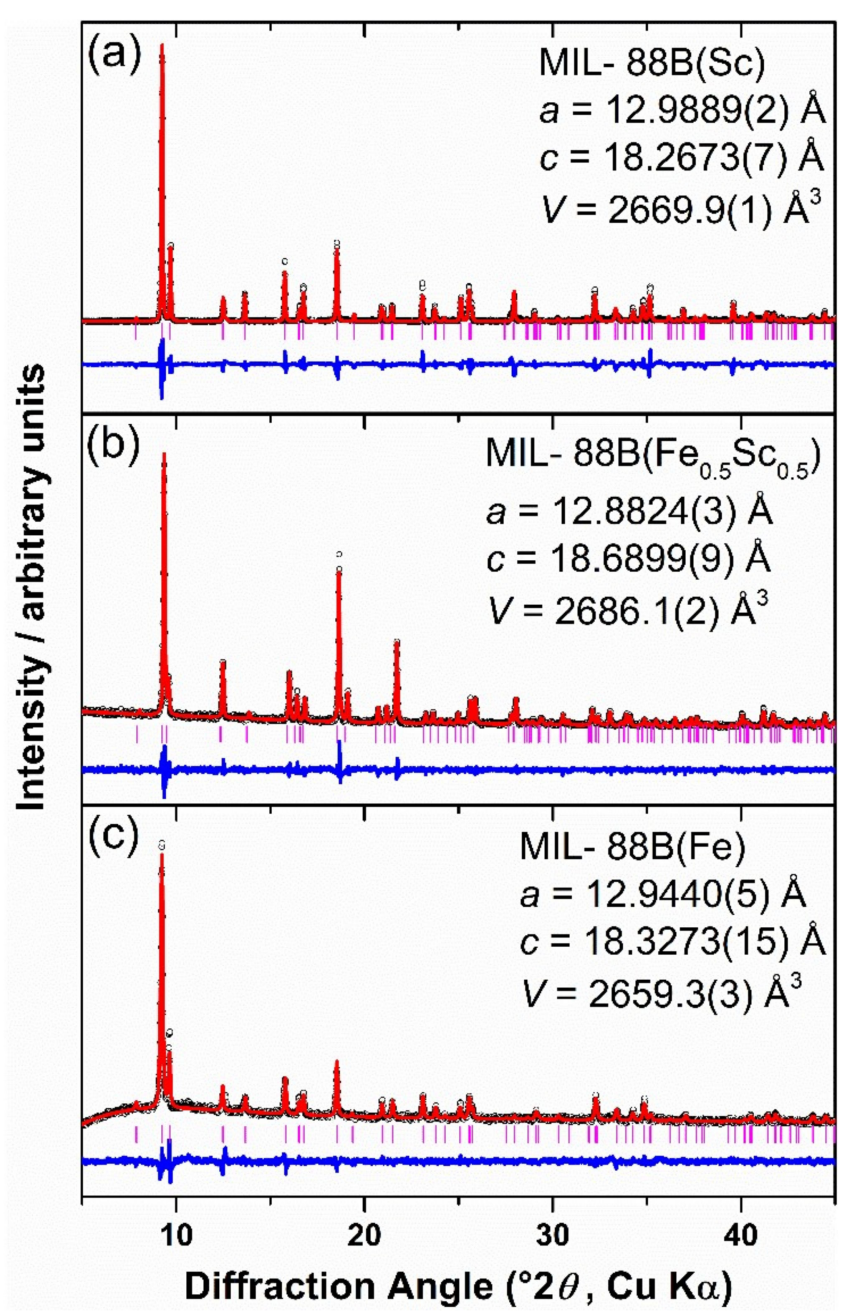

Figure 5. Profile fits to powder X-ray diffraction patterns of (a) MIL-88B(Sc), (b) MIL-88B(Fe $\left.{ }_{0.5} \mathrm{Sc}_{0.5}\right)$, and (c) MIL- $88 \mathrm{~B}(\mathrm{Fe})\left(\mathrm{Cu} K \alpha_{1}\right.$ radiation) fitted using space-group $P \overline{6} 2 c$. The points are the measured data, the red line is the final fit, the blue line is the difference curve and the pink ticks are the positions of the allowed reflections. Refined lattice parameters and unit cell volumes are provided on each panel.

In addition to the different unit cell of the mixed-metal material, more substantive evidence for the formation of a mixed-metal sample of the MOF, rather than a phase-separated mixture of materials, comes from EDX mapping on the SEM, Figure 6. This shows how the two metals are both present in micro-sized crystallites of MIL-88B $\left(\mathrm{Sc}_{0.5} \mathrm{Fe}_{0.5}\right)$. Proving the degree of mixing of the two metals on smaller length-scales is challenging; in the previous work on MIL- $100(\mathrm{Fe}, \mathrm{Sc})$, which contains the same trimeric building units as found in MIL-88B, it was impossible to determine, using extended X-ray absorption fine structure (EXAFS) spectroscopy, whether the individual clusters contained mixtures of metals or whether single metal clusters were present [41]. 

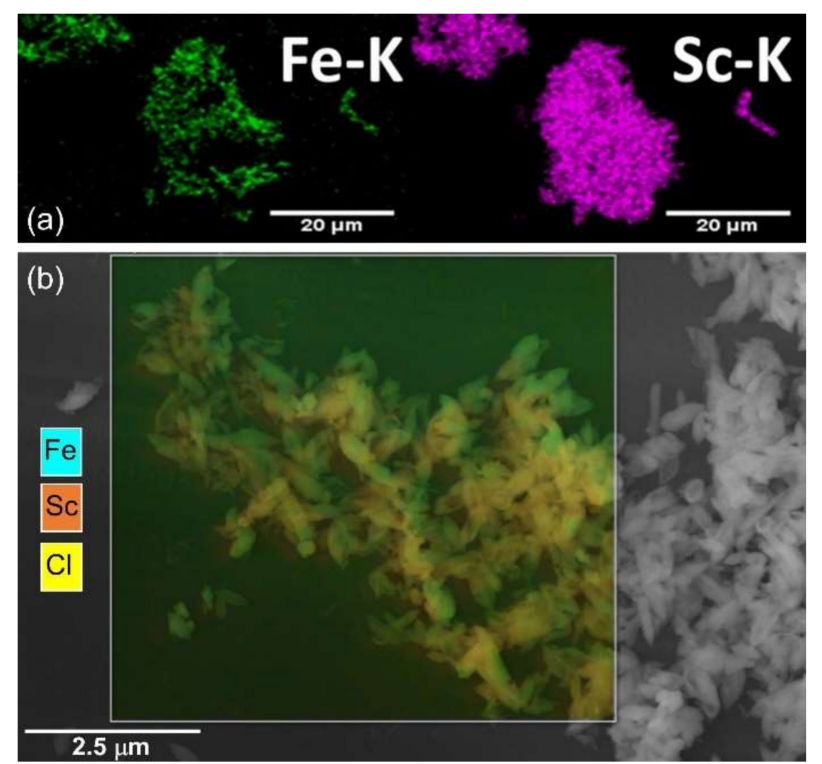

Figure 6. Elemental maps of MIL- $88 \mathrm{~B}\left(\mathrm{Fe}_{0.5} \mathrm{Sc}_{0.5}\right)$ at two magnifications showing the distribution of the two metals, and the presence of chlorine.

The elemental mapping suggests that the concentration of iron in the MIL- $88 \mathrm{~B}(\mathrm{Fe}, \mathrm{Sc})$ sample is lower than that of scandium, despite the initial 1:1 molar ratio used in synthesis. This was verified by bulk analysis for metals using ICP-OES, which gave a Sc:Fe molar ratio of 3.1:1. X-ray photoelectron spectroscopy (XPS, Figure 7), was used to quantify the metal ratio at the surface of the material, and integration of the signal gave a Sc:Fe ratio of 6.0:1. The typical depth of the XPS analysis for these elements is around $5-10 \mathrm{~nm}$, which shows how the surface of the particles is scandium-rich. First, this suggests that most of the Fe is present within the crystallites of the MIL-88B, and, second, shows how the surface is terminated substantially by Sc-containing species, which are strongly bound, since they are not removed by the washing used in the sample preparation. One possible explanation for the excess scandium at the surface is the presence of a scandium chloride species, necessary for charge-balance of the terminated crystal surfaces. Some of the XPS signal can indeed be accounted for as $\mathrm{ScCl}_{3}$ (Figure 7a), and this result is also consistent with the presence of chlorine detected in the EDXA mapping on the SEM. The majority of signal ( $>80 \%$ ) in the Sc $2 p_{3 / 2}$ region (Figure $7 \mathrm{a}$ ), however, can be accounted for by the presence of octahedrally coordinated scandium, assigned using $\mathrm{ScOOH}$ as a reference, as expected for the MIL-88B structure. The Fe $2 p_{3 / 2}$ region of the XPS (Figure $7 \mathrm{~b}$ ) is more complex due to multiplet splitting [53-56]. Careful analysis of the overall Fe $2 p_{3 / 2}$ envelope necessitated a component at around $709 \mathrm{eV}$, indicating the presence of a significant amount of $\mathrm{Fe}^{2+}$ as well as $\mathrm{Fe}^{3+}$. This is unlike the spectrum of the single metal MIL-88B(Fe) (Supplementary Materials) that shows $>90 \% \mathrm{Fe}^{3+}$, as expected, and would suggest that the mixed-metal material contains defects (see below for a further discussion of this). 

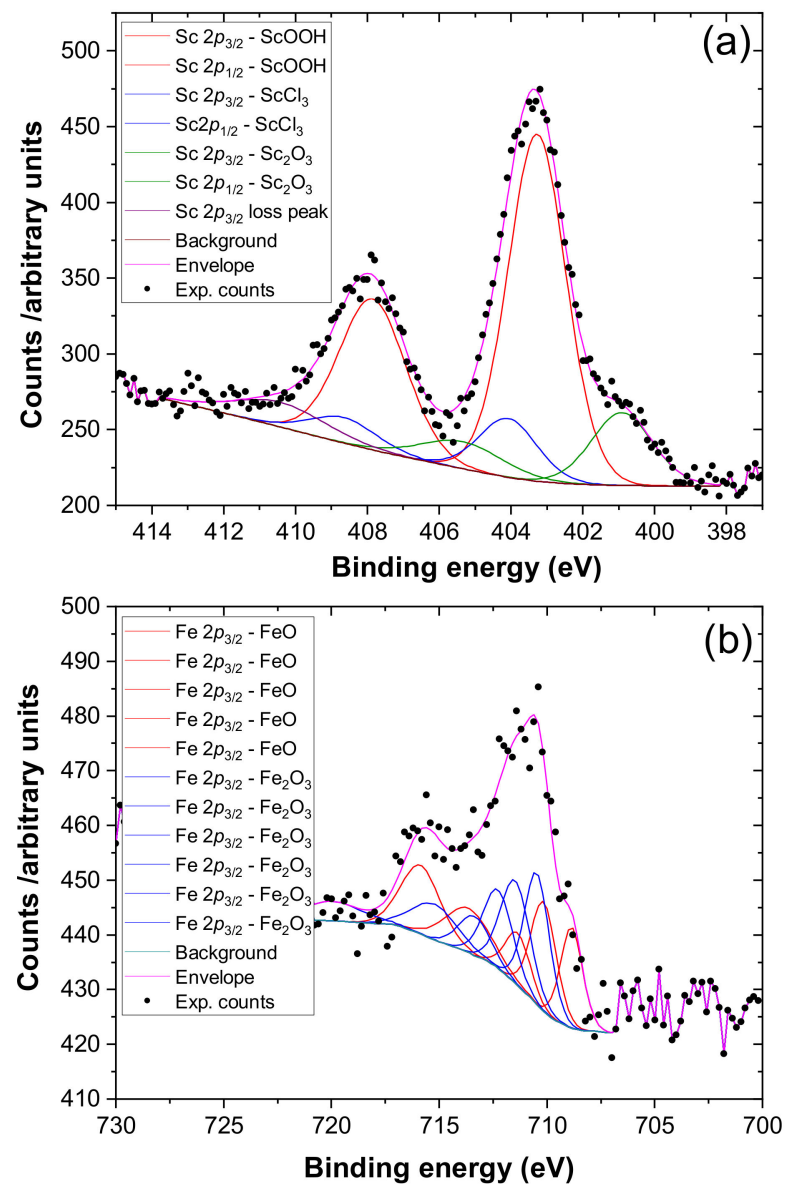

Figure 7. X-ray photoelectron spectra of MIL- $88 \mathrm{~B}(\mathrm{Fe}, \mathrm{Sc})$ in (a) the $\mathrm{Sc} 2 p$ region and (b) the Fe $2 p_{3 / 2}$ region. The fitted contributions are shown with reference spectra in the literature used for guidance (see text).

The FT-IR spectra of the MIL-88B materials (Figure 8) shows all the vibrational bands characteristic of framework-coordinated carboxylate groups expected in the MIL-88B structure, and further evidence for the isostructural nature of the samples (see Supplementary Materials for assignment of the spectra). Some weak additional bands in the spectrum of the MIL- $88(\mathrm{Fe}, \mathrm{Sc})$ sample suggest the presence of some uncoordinated (protonated) carboxylic acid groups. This is not due to the presence of crystalline $\mathrm{H}_{2} \mathrm{BDC}$ (not seen in the powder XRD, Figure 5, and which also has a different FT-IR spectrum), and therefore suggests a defective structure for the mixed-metal material, with some linkers that do not bridge pairs of clusters. The thermogravimetric analysis (TGA) data (Supplementary Materials) show that all the solvents and water molecules in MIL-88B materials are removed at above $\sim 150{ }^{\circ} \mathrm{C}$. On continued heating, a decomposition of the MIL-88B network occurs above $450{ }^{\circ} \mathrm{C}$, forming $\mathrm{Fe}_{2} \mathrm{O}_{3}$ and/or $\mathrm{Sc}_{2} \mathrm{O}_{3}$ as the final product, which is consistent with the literature [47]. The TGA of the mixed-metal material (Supplementary Materials) shows an extra inflection in mass loss in the region corresponding to the combustion of the linker, which is consistent with the presence of some partially coordinated benzene-1,4-dicarboxylate groups. This is consistent with the more defective structure of this material, also indicated by IR, and charge balance in the material may be explained by the presence of some $\mathrm{Fe}^{2+}$ that was seen by XPS, as discussed above. 


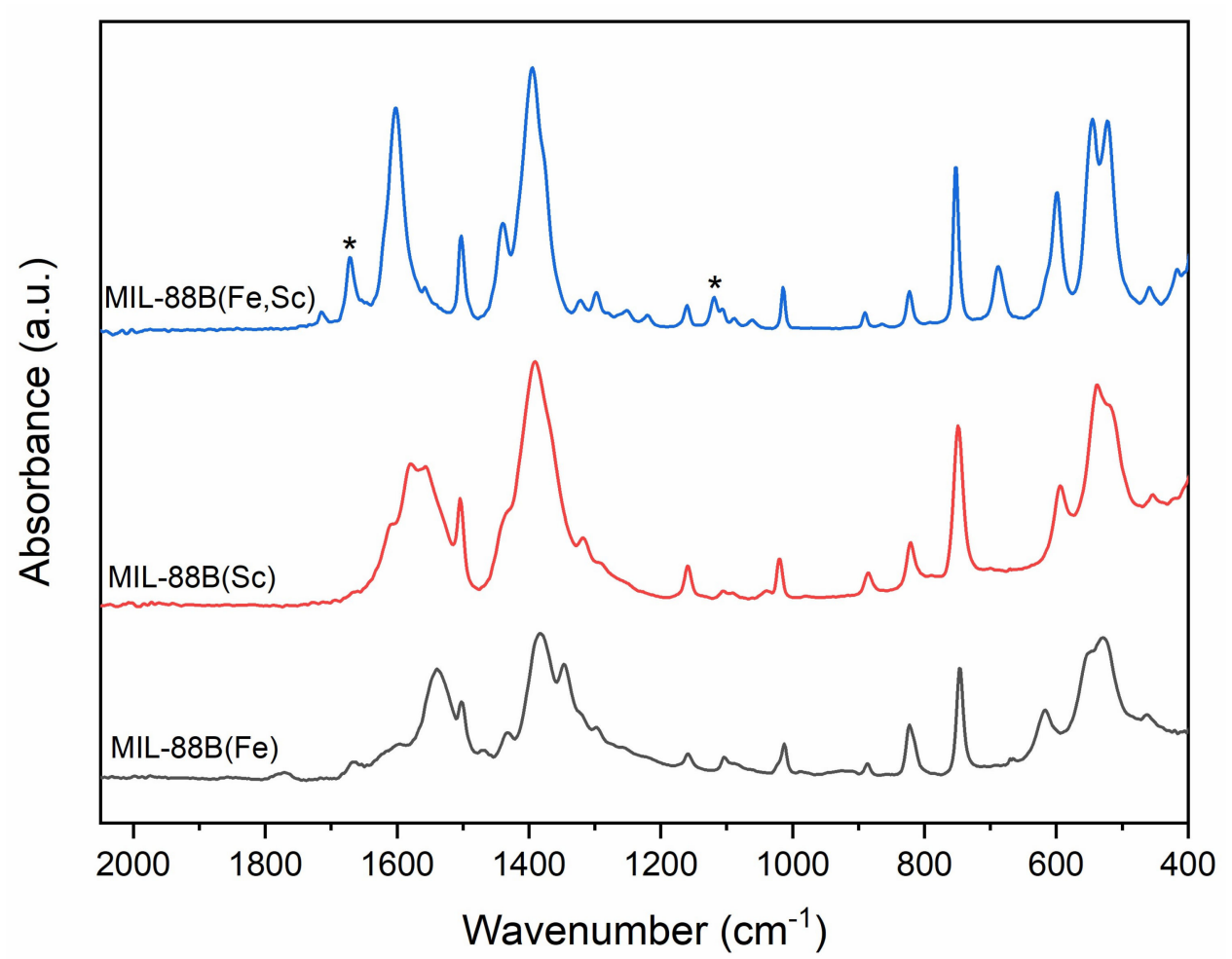

Figure 8. Infrared spectra of MIL-88B materials. The features labelled * are assigned as due to uncoordinated carboxylic acid groups.

Three samples were selected to examine their effectiveness as catalysts for glucose conversion: MIL-88B(Fe), MIL-88B(Fe,Sc), and MIL-88B(Sc). Given the instability of the materials in water, DMSO was used as the reaction solvent, in which the materials proved to be stable (Figure 4). The catalytic results are summarised in Table 1, which shows the total glucose conversion as well as the three desired products analysed for: fructose, mannose, and 5-HMF. We report results from two different catalyst loadings (based on mass, 30:1 and 7.5:1, glucose to catalyst ratio) and at two different temperatures (120 ${ }^{\circ} \mathrm{C}$ and $140{ }^{\circ} \mathrm{C}$ ). Firstly, it is important to note that DMSO alone, in the absence of any catalyst, results in a conversion of just $1.6 \%$ at $120^{\circ} \mathrm{C}$ and $60.3 \%$ at $140{ }^{\circ} \mathrm{C}$. However, the product mixture contains only a minor amount of 5-HMF at the upper reaction temperature and neither of the intermediate sugars, fructose or mannose, are present, which suggests a decomposition pathway that does not yield these desired products. Indeed, Jia et al. found that anhydrous DMSO alone gave cellobiose as the main dehydration product of glucose at $130^{\circ} \mathrm{C}$ for 2 hours [57]. In the presence of the MIL-88B solids, a much more significant formation of 5-HMF is seen, along with the intermediate fructose and mannose sugars. DMSO is known to act as a catalyst for the dehydration of fructose to 5-HMF in the absence of any Brønsted acid at $150{ }^{\circ} \mathrm{C}$ [58]. This implies that the MIL-88B acts as a Lewis acid catalyst that produce the fructose by glucose isomerisation, which can then be converted to 5 -HMF by the DMSO solvent.

The mixed-metal MIL-88B $(\mathrm{Fe}, \mathrm{Sc})$ gives the highest conversion $(70.7 \%)$ and $5-\mathrm{HMF}$ yield $(24.9 \%)$ at $140{ }^{\circ} \mathrm{C}$ with a 7.5 substrate-catalyst ratio. This catalyst thus produces significant amounts of 5-HMF from glucose. The mixed-metal material is more effective than either the MIL-88B(Fe) or MIL-88B(Sc), which may be due to greater structural disorder leading to a greater concentration of defects, such as coordinatively unsaturated metal sites, implying more Lewis acid sites. As noted above, the degree of mixing of the metals is difficult to prove unambiguously, but since the mixed-metal material always gives a higher glucose conversion than either of the single metal materials, there must be a cooperative effect, which in turn suggests that the two metals are in close proximity. In previous work on MIL-100(Sc), it was noted that upon addition of excess Fe, the presence of small amounts of amorphous $\mathrm{Fe}_{2} \mathrm{O}_{3}$ enhanced the Lewis acidity [41], so it is possible that we are seeing the same 
beneficial effect here, although the presence of small amounts of an amorphous second phase is difficult to determine.

The effect of temperature is also significant on the catalysis. At the temperature of $120^{\circ} \mathrm{C}$ and the catalyst-to-substrate ratio of 7.5, the selectivity towards 5-HMF is notably higher over the mixed-metal material compared to Fe-only material $(16.8 \%$ vs $1.7 \%)$. At the lower catalyst-to-substrate ratio of 30:1, the mixed-metal material shows a slightly lower activity than the Fe-only material, but a notably higher 5-HMF selectivity. The varying response of the two materials to temperature at both catalyst loadings is consistent with a different, and more favourable, mode of action in the mixed-metal material. Interestingly, the scandium material has a higher selectivity to 5-HMF than the iron at the catalyst low loadings, yet lower total conversion, providing evidence that each metal has a distinct role in the catalysis. Vlachos and co-workers studied the kinetics and mechanism of tandem Lewis-Brønsted acid catalysis of the same reaction, and reported that relative Lewis-Brønsted acid concentration has an optimum and pronounced effect on 5-HMF yield, which leads to 5-HMF yield being maximised due to a change in the rate-limiting step from fructose dehydration to glucose isomerisation [59]. In this sense, the MIL-88B(Fe) catalyst shows the formation of fructose both at $120^{\circ} \mathrm{C}$ and $140{ }^{\circ} \mathrm{C}$; however, the MIL-88B(Sc) catalyst yields higher 5-HMF yields. On the other hand, the mixed-metal MIL-88B(Fe,Sc) yields the highest 5-HMF yields, which is more clearly pronounced at $140{ }^{\circ} \mathrm{C}$. Hence, the origin of the behaviour of our catalysts may be due to the distribution and availability of acid sites.

We considered the recyclability of the MIL- $88 \mathrm{~B}(\mathrm{Fe}, \mathrm{Sc})$ catalyst by isolating the solid after a run, washing with DMSO, and adding fresh reagents (Figure 9). This was done at a larger scale than the screening reactions reported in Table 1 so mass transport may be different; however, the material maintains activity after three cycles and only after the fourth use shows a notable drop in glucose conversion. The recycling of MOF catalysts has not always been reported in the literature, but for the results that are available, we note that, although the recyclability of MIL- $88 \mathrm{~B}(\mathrm{Fe}, \mathrm{Sc})$ is not as complete as for some sulfonated MIL-101(Cr) materials (albeit under different reaction conditions) [27,29], others have noted that the build-up of humins can make recycling difficult [10]. Nevertheless, the observation of recyclability points towards the use of the materials in continuous reactors, as has been achieved for sulfonated MIL-101(Cr) in a fixed-bed system [26]; here, conversion need not be high to generate useful quantities of the desired product.

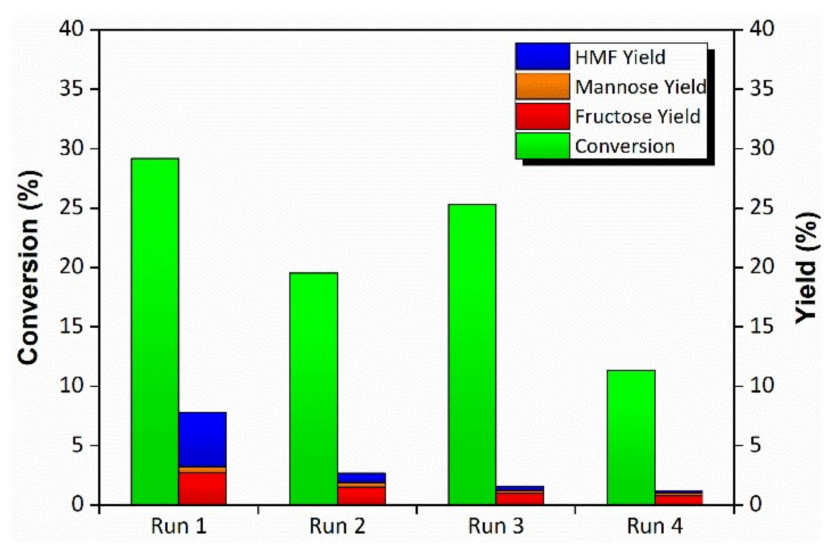

Figure 9. Recyclability of MIL-88B(Fe,Sc) as a catalyst for glucose conversion $\left(120^{\circ} \mathrm{C}\right.$ in DMSO for 3 hours).

In comparison to other MOF-based solid acids that have been recently investigated as catalysts for glucose conversion, the MIL- $88 \mathrm{~B}(\mathrm{Fe}, \mathrm{Sc})$ shows favourable properties. Tsapatsis and co-workers have recently showed that a composite of MIL-101(Cr) and nanoparticles of $\mathrm{Cr}(\mathrm{OH})_{3}$ gave the highest conversion of glucose in a two-step process with ethanol as the solvent for isomerisation to ethyl fructoside, followed by the addition of water to allow hydrolysis to fructose, each performed at $100{ }^{\circ} \mathrm{C}$ for 24 hours: the catalyst was more effective than a physical mixture of the two component solids and 
various other MIL-101(Cr) materials, but also outperformed the zeolite Sn-beta giving $>75 \%$ conversion, with almost $60 \%$ of the product fructose [29]. Yabushita et al. used the zirconium MOF NU-1000 modified with phosphate to optimise the 5-HMF yield from glucose and also screened various solvent mixtures: for their catalysis, however, water-DMSO gave the lowest overall glucose conversion in comparable conditions to those we have used (at $140^{\circ} \mathrm{C}$ for 5 hours), and THF or propanols as solvents gave almost complete conversion [30]. Looking at other solid catalysts applied in DMSO solvent, the recent work of $\mathrm{Li}$ et al. on $\mathrm{MnO}_{2}$ particles surface modified with $\mathrm{Sn}^{4+}$-containing coordination polymers provides a useful comparison [60]. Their catalyst achieved $\sim 56 \%$ conversion at $150{ }^{\circ} \mathrm{C}$ in 5 hours, with a $60 \%$ selectivity towards 5-HMF, which was superior to other Sn-based catalysts reported in the literature in DMSO solvent. Therefore, the MIL- $88 \mathrm{~B}(\mathrm{Fe}, \mathrm{Sc})$ catalyst is comparable to the Sn-based catalyst (with higher conversion, although lower selectivity), but has the advantage of being prepared in a single-step, rather than being a surface-modified composite material. Other reported systems that show a higher conversion of glucose to 5-HMF in DMSO involve a multi-step synthesis of the catalyst and strong mineral acids. This includes Sn-containing vanadium phosphate, prepared in three steps starting from a phosphoric acid treatment of vanadium oxide [61]; sulfated mesoporous niobium oxide prepared in several steps, involving ultrasound and hydrothermal treatments, with a final sulfuric acid treatment [62]; and sulfated zirconia materials that are activated using chlorosulfonic acid in ethylene dichloride [63].

The nature and location of the Lewis acid sites in MOF catalysts have not been extensively studied in glucose isomerisation reactions, and the accessibility of active sites will depend on the substrates used. Ammonia temperature-programmed desorption (TPD) was used to characterise the MIL-88B(Fe,Sc) material (Figure 10), and this confirms the presence of surface acid sites at a concentration of $0.36 \mathrm{mmol} \mathrm{g}^{-1}$. The results are complicated by the onset of collapse of the MOF at higher temperatures (see TGA in Supplementary Materials), but a desorption event between 100 and $300{ }^{\circ} \mathrm{C}$ is characteristic of the interaction of ammonia with surface acid sites. This is similar behaviour to that reported for the $\mathrm{Cu}$-containing MOF-74 by Jiang et al., who observed desorption of ammonia around $100-250{ }^{\circ} \mathrm{C}$ under similar conditions [64].

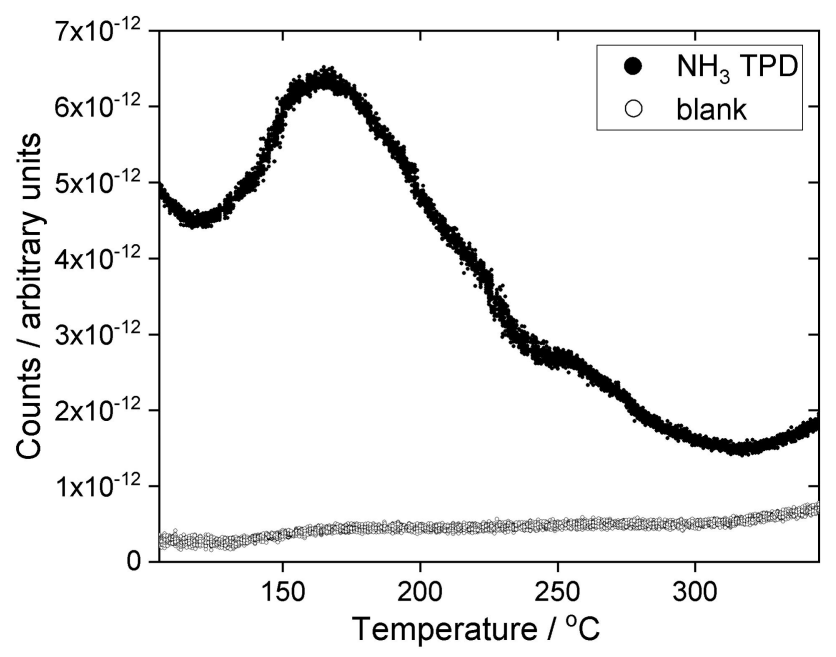

Figure 10. Temperature-programmed desorption of ammonia from MIL-88B(Fe,Sc), with data from a fresh sample of the material (without ammonia adsorbed) heated under the same conditions as a blank. 
Table 1. Results of catalytic conversion of glucose using MIL-88B catalysts. All reactions were performed in DMSO and the results reported are after 3 hours of reaction time. Product selectivity is defined as $100 \times$ (product yield/conversion)

\begin{tabular}{|c|c|c|c|c|c|c|c|c|c|}
\hline \multirow{2}{*}{ Temperature $\left({ }^{\circ} \mathrm{C}\right)$} & \multirow{2}{*}{$\begin{array}{l}\text { Substrate to Catalyst } \\
\text { Ratio (wt./wt.) }\end{array}$} & \multirow{2}{*}{ Catalyst } & \multirow{2}{*}{ Conversion (\%) } & \multicolumn{3}{|c|}{ Product Yield (\% Mole) } & \multicolumn{3}{|c|}{ Product Selectivity (\% Mole) } \\
\hline & & & & Fructose & Mannose & 5-HMF & Fructose & Mannose & 5-HMF \\
\hline \multirow{4}{*}{120} & $\infty$ & none & 1.6 & 0.0 & 0.0 & 0.01 & 0.0 & 0.0 & 0.69 \\
\hline & \multirow{3}{*}{$30: 1$} & MIL-88B(Fe) & 18.9 & 6.3 & 0.3 & 0.0 & 33.3 & 1.6 & 0.0 \\
\hline & & MIL-88B(Sc) & 9.1 & 1.0 & 0.4 & 0.1 & 11.0 & 4.4 & 1.1 \\
\hline & & MIL-88B(Fe,Sc) & 11.5 & 1.1 & 0.2 & 0.7 & 9.6 & 1.7 & 6.1 \\
\hline \multirow{4}{*}{140} & $\infty$ & none & 60.3 & 0.0 & 0.0 & 0.6 & 0.0 & 0.0 & 1.0 \\
\hline & \multirow{3}{*}{$30: 1$} & MIL-88B(Fe) & 54.2 & 7.6 & 1.2 & 0.9 & 14.0 & 2.2 & 1.7 \\
\hline & & MIL-88B(Sc) & 28.8 & 2.1 & 1.1 & 3.2 & 7.3 & 3.8 & 11.1 \\
\hline & & MIL-88B(Fe,Sc) & 53.3 & 3.6 & 2.0 & 17.8 & 6.8 & 3.8 & 33.4 \\
\hline \multirow{2}{*}{120} & \multirow{2}{*}{$7.5: 1$} & MIL-88B(Fe) & 24.2 & 3.2 & 0.0 & 0.4 & 13.2 & 0.0 & 1.7 \\
\hline & & MIL-88B(Fe,Sc) & 19.7 & 0.8 & 2.3 & 3.3 & 4.1 & 11.7 & 16.8 \\
\hline \multirow{2}{*}{140} & \multirow{2}{*}{$7.5: 1$} & MIL-88B(Fe) & 55.6 & 3.6 & 1.0 & 3.8 & 6.5 & 1.8 & 6.8 \\
\hline & & MIL-88B(Fe,Sc) & 70.7 & 3.3 & 1.4 & 24.9 & 4.7 & 2.0 & 35.2 \\
\hline
\end{tabular}


While MIL-88B is a porous, breathing framework in the presence of certain solvents [51], it is likely that the bulky glucose does not penetrate into the MOF structure, but the activity is instead associated with the surface of the crystallites. Additional PXRD measurements made on samples immersed in DMSO show no evidence for pore-opening in this solvent at room temperature (Supplementary Materials), so it is probable that the material remains in a contracted form during the catalysis. Indeed, after catalysis and ammonia TPD, there is no evidence for pore swelling in the PXRD (Supplementary Materials). Our measured BET surface area of $16 \mathrm{~m}^{2} \mathrm{~g}^{-1}$ for MIL-88B(Fe,Sc) activated in vacuum at $100{ }^{\circ} \mathrm{C}$ corroborates this, showing the lack of porosity and a surface area as expected for micron-sized powders. This result is similar to that reported for other MIL-88B(Fe) materials: for example, Rahmani and Rahmani measured a BET surface area of $23 \mathrm{~m}^{2} \mathrm{~g}^{-1}$ [65], while Vuong et al. found a surface area of $30 \mathrm{~m}^{2} \mathrm{~g}^{-1}$ for a hydrated, mixed (Fe, Ni) form of the material with amino-functionalised linkers [66]. Previous work on dense (non-porous) scandium-organic frameworks has shown how surface Lewis acidity is sufficient for the acetalization of aldehydes or the cyanosilylation of carbonyl compounds $[67,68]$. Although Mitchell et al. found that MIL-88B(Sc) was an inferior Lewis acid catalyst compared to porous MIL-100(Sc) in a variety of organic transformations [41], which they attributed to its low surface area, in DMSO it is clear that the Lewis acidity is sufficient for the glucose isomerisation.

\section{Discussion}

The MIL-88B material provides the Lewis acidity that catalyses isomerisation of glucose to fructose, and a cooperative effect of the Fe and Sc in the mixed-metal MIL-88B MOF provides optimum catalytic activity to maximise the 5-HMF yields, while the DMSO solvent catalyses the fructose dehydration to 5-HMF. It is notable that the mixed-metal material shows enhanced reactivity compared to the iron or scandium catalysts, and the presence of a locally disordered structure, such as uncoordinated ligands, may be partly responsible for this. Further work is needed to elucidate the mechanism of reaction, such as NMR studies with isotopic substitution, especially since it is likely that the surface of the MOF crystallites provides the active sites for catalysis and that solvent effects may be at play in this chemistry, but our work shows how one-step synthesis of MOF catalysts under moderate conditions provides a convenient route to acid catalysts for biomass transformations. The long-term stability of the catalysts and their implementation in flow reactors is the next step towards realistic use.

\section{Materials and Methods}

\subsection{Materials and Chemicals}

All reagents were purchased and used without further purification. $\mathrm{FeCl}_{3} \cdot 6 \mathrm{H}_{2} \mathrm{O}(99.9 \%)$ was obtained from Sigma Aldrich (Gillingham, United Kingdom). $\mathrm{ScCl}_{3} \cdot 6 \mathrm{H}_{2} \mathrm{O}(99.9 \%)$ and benzene-1,4-dicarboxylic acid $\left(\mathrm{H}_{2} \mathrm{BDC}, 98 \%\right)$ were obtained from Alfa Aesar (Heysham, United Kingdom). Monosodium 2-sulfobenzene-1,4-dicarboxylate $\left(\mathrm{NaH}_{2} \mathrm{MSBDC}\right)$ was obtained from Tokyo Chemical Industry (TCI, >98\%, Tokyo, Japan). DMF was purchased from Fischer Scientific (Loughborough, United Kingdom) and absolute ethanol was purchased from VWR Chemicals.

\subsection{Synthesis of MIL-101(Fe,Sc)}

MIL-101(Fe) was prepared following the method of Zhu et al. [43], $\mathrm{FeCl}_{3} \cdot 6 \mathrm{H}_{2} \mathrm{O}(0.894 \mathrm{~g}, 3.3 \mathrm{mmol})$, $\mathrm{H}_{2} \mathrm{BDC}(0.280 \mathrm{~g}, 1.65 \mathrm{mmol})$, and DMF $(20 \mathrm{ml})$ were mixed with stirring at room temperature for $2 \mathrm{~h}$. The mixture was transferred to a Teflon-lined autoclave $(45 \mathrm{~mL})$ and heated at $383 \mathrm{~K}$ for either 3 or 40 hours (see below). After cooling to room temperature, the mixture was filtered and the solid product was washed with ethanol $(20 \mathrm{~mL})$ at $60^{\circ} \mathrm{C}$ for $3 \mathrm{~h}$. The product was dried at $60^{\circ} \mathrm{C}$ overnight. Variation of metal ratio (Fe:Sc) and ligand using MSBDC in place of $\mathrm{BDC}$ was investigated by following the same synthesis method, but replacing the $\mathrm{FeCl}_{3} \cdot 6 \mathrm{H}_{2} \mathrm{O}$ with $\mathrm{ScCl}_{3} \cdot 6 \mathrm{H}_{2} \mathrm{O}$ and/or the $\mathrm{H}_{2} \mathrm{BDC}$ with $\mathrm{NaH}_{2} \mathrm{MSBDC}$. 


\subsection{Synthesis of MIL-88B(Sc)}

For comparison, MIL-88B(Sc) was prepared using a method based on that of Mowat et al. [39], where $0.22 \mathrm{~g}$ ( $1.45 \mathrm{mmol})$, scandium (III) chloride, $0.14 \mathrm{~g}(8.43 \mathrm{mmol}) \mathrm{H}_{2} \mathrm{BDC}$, and $9 \mathrm{~mL}$ DMF (Fisher Scientific) were stirred for 5 minutes prior to transfer into a $45 \mathrm{~mL}$ Teflon -lined autoclave and heated to $140{ }^{\circ} \mathrm{C}$ for $48 \mathrm{~h}$ before cooling to room temperature. The solid product was isolated by suction filtration and washed with $25 \mathrm{~mL}$ ethanol by stirring at room temperature for $24 \mathrm{~h}$. The recovered solid was finally dried at $70^{\circ} \mathrm{C}$ in the air for $24 \mathrm{~h}$.

\subsection{Materials Characterisation}

For sample identification, PXRD patterns were recorded on a D5000 Siemens diffractometer with $\mathrm{Cu} \mathrm{K} \alpha_{1 / 2}$ radiation $\left(\lambda=1.54184 \AA\right.$ ) and $2 \theta=2-30^{\circ}$ (step size $0.02^{\circ}$ in $2 \theta$ ), operated at $40 \mathrm{kV}$ and $40 \mathrm{~mA}$. High resolution PXRD patterns were recorded using a Panalytical X'Pert Pro MPD (Malvern Panalytical, Malvern, United Kingdom), equipped with monochromatic $\mathrm{Cu} \mathrm{K}_{\alpha 1}$ radiation $(\lambda=1.54056$ $\AA$ ) and a PIXcel solid state detector. Profile fitting of the powder patterns was performed using the GSAS software (revision 1188, Los Alamos, USA) [69] implemented using the EXPGUI interface [70]. FT-IR spectra were measured at room temperature in the range $400-4000 \mathrm{~cm}^{-1}$ using a Platinum-ATR Bruker Alfa instrument (Bruker Optics GmbH, Ettlingen, Germany). The stability of the catalysts was investigated by TGA using a Mettler Toledo TGA/DSC1 instrument (Leicester, United Kingdom) under ambient air pressure and a heating rate of $10{ }^{\circ} \mathrm{C} \mathrm{min}^{-1}$. Samples were heated in air from $25^{\circ} \mathrm{C}$ to $1000^{\circ} \mathrm{C}$. Selected elemental compositions of materials were determined by energy dispersive X-ray (EDX) analysis using a FEI scanning electron microscope (SEM, Fei UK Limited, Altrincham, United Kingdom). Elemental analysis for metals was performed by MEDAC Ltd, Surrey, United Kingdom, using the ICP-OES method after acid digestion. XPS was measured using a Kratos AXIS Ultra DLD (Manchester, United Kingdom). XPS measurements were carried out in a UHV system with a base pressure of $5 \times 10^{-11}$ mbar. The sample was excited with X-rays from a monochromated $\mathrm{Al} \mathrm{K \alpha}$ source $(1486.7 \mathrm{eV})$, with the photo-electrons being detected at a $90^{\circ}$ take-off angle with respect to the sample surface. Curve fitting was performed using the CasaXPS package, incorporating Voigt (mixed Gaussian-Lorentzian) line shapes and Shirley backgrounds for all regions except the Sc $2 p$ region, where a U 2 Tougaard background was found to be more appropriate.

The acidity of materials was characterised using ammonia TPD. An excess of $0.02 \mathrm{vol} \%$ ammonia in helium was dosed onto $50-70 \mathrm{mg}$ of a catalyst contained in a quartz tube at $100{ }^{\circ} \mathrm{C}$ (to minimise physisorption). The ammonia was then desorbed from the catalysts by heating the material to $350{ }^{\circ} \mathrm{C}$ at a ramp rate of $2{ }^{\circ} \mathrm{C} \mathrm{min}^{-1}$. To ensure the complete desorption of ammonia from the material, the temperature was then maintained at $350{ }^{\circ} \mathrm{C}$ for 6 hours. The amount of ammonia desorbed from the catalyst was measured using a mass spectrometer at $\mathrm{m} / \mathrm{z}=17$ with the interference with water vapour taken into account. A blank experiment (used as a baseline) was performed with a fresh catalyst, but without ammonia pre-adsorption. Surface area measurements were performed using nitrogen adsorption via the Brunauer-Emmett-Teller (BET) method using a QUADRASORB (gas sorption surface area analyzer) (Quantachrome UK, Hook, United Kingdom) after degassing samples under vacuum at $100{ }^{\circ} \mathrm{C}$.

\subsection{Catalytic Tests}

Catalytic screening was carried out in $4 \mathrm{~mL}$ batch reactors at $393 \mathrm{~K}$ or $413 \mathrm{~K} .3 \mathrm{~mL}$ of $10 \mathrm{wt}$ \% glucose solution (in DMSO) was heated to the desired temperature together with the MOF catalyst and a magnetic stirring bar (either 10 or $40 \mathrm{mg}$, corresponding to a 30 or 7.5 substrate:catalyst ratio, respectively) for 3 hours. Blank experiments were also carried out without catalyst. The products were analysed by high performance liquid chromatography (HPLC) equipped with a Bio-Rad HPX 87P column; a photo diode array detector and evaporative light scattering detector (ELSD) were used to monitor 5-HMF and sugars, respectively. The mobile phase was water with $0.6 \mathrm{~mL} \mathrm{~min}{ }^{-1}$ flow 
rate. The products and the reactant (glucose) were quantified by calibration with external standard solutions. Recycle reactions were conducted in a $25 \mathrm{~mL}$ reactor with PTFE lining (Berghof, BR-25). In a typical reaction, $200 \mathrm{mg}$ of catalyst and a magnetic stirring bar was placed into the reactor. $15 \mathrm{~mL}$ of a solution of $10 \mathrm{wt}$. \% glucose in DMSO was then added. The reactor was sealed and pressurized to 10 bar with helium. The reactor was brought to reaction temperature $\left(120^{\circ} \mathrm{C}\right)$ by placing it into a preheated aluminium block heated via a heating/stirring plate. At the end of the reaction ( 3 hours), the reactor was removed from the heating block and quenched in an ice bath at $0{ }^{\circ} \mathrm{C}$ to stop the reaction. The reactor was then depressurised and opened. The solid catalyst was recovered from the reaction solution using a centrifuge and washed with DMSO. The reaction solution was filtered and analysed using a Shimadzu HPLC (Shimadzu UK Ltd, Milton Keynes, United Kingdom), as described above. In the subsequent reaction tests, the recovered catalyst was added back into the $25 \mathrm{~mL}$ reactor along with fresh stock solution. The reaction procedure was then repeated under the same conditions in order to test the recyclability of the catalyst, and products were analysed as described above.

\section{Conclusions}

The replacement of $\mathrm{Cr}^{3+}$ in MIL-101 by more benign metal cations, $\mathrm{Fe}^{3+}$ and $\mathrm{Sc}^{3+}$, leads to an instability of the structure and the formation of the polymorphic MOF MIL-88B structure. Although MIL-88B(Fe,Sc) materials are unstable under aqueous hydrothermal conditions, they are stable in DMSO at $140{ }^{\circ} \mathrm{C}$ and efficiently transform glucose to 5-HMF with high conversion and selectivity. While DMSO is less desirable as a solvent than water, the simplicity of the synthesis of the MIL-88B catalyst materials in a single-step is a significant advantage over the more conventional solid-acid catalysts that have so far been proposed for this reaction.

Supplementary Materials: Additional characterisation data. The following are available online at http://www. mdpi.com/2073-4344/9/5/437/s1. Figure S1: XPS of MIL-88B(Fe), Table S1: Assignment of key bands in the IR spectra, Figure S2: Thermogravimetric analysis of MIL-88B catalysts, Figure S3: Powder on samples immersed in DMSO, Figure S4: Powder XRD of MIL-88(Fe,Sc) as-made, after catalysis, and after ammonia TPD.

Author Contributions: Conceptualization, V.D., Y.K.K., and R.I.W.; Formal Analysis, R.P., R.O., D.L.B, T.W.C, N.C., M.W., R.J.K.; Investigation, R.P., R.O., D.L.B, T.W.C, N.C., M.W., R.J.K.; Writing-Original Draft Preparation, R.P, and R.I.W.; Writing-Review and Editing, R.P., R.O., D.L.B., Y.K.K, V.D.; Supervision, V.D., Y.K.K., and R.I.W.; Project Administration, V.D., Y.K.K., and R.I.W.; Funding Acquisition, V.D., Y.K.K., and R.I.W.

Acknowledgments: This work was supported by the Royal Society [Challenge Grant CH160099], the UK Engineering and Physical Sciences Research Council (EPSRC) [grant EP/P511432/1 Global Challenge Research Fund (GCRF) Institutional Award for the University of Warwick], and a Research Grants for Higher Education 2016 from DGHE, Indonesia [No.1136/UN2.R12/HKP/05.00/2016]. We thank Baiwen Zhao for his assistance with measuring surface area. The data supporting this article are available at https://wrap.warwick.ac.uk/116888.

Conflicts of Interest: The authors declare no conflict of interest. The sponsors had no role in the design, execution, interpretation, or writing of the study.

\section{References}

1. Rosatella, A.A.; Simeonov, S.P.; Frade, R.F.M.; Afonso, C.A.M. 5-Hydroxymethylfurfural (HMF) as a building block platform: Biological properties, synthesis and synthetic applications. Green Chem. 2011, 13, 754-793. [CrossRef]

2. Van Putten, R.J.; van der Waal, J.C.; de Jong, E.; Rasrendra, C.B.; Heeres, H.J.; de Vries, J.G. Hydroxymethylfurfural, a Versatile Platform Chemical Made from Renewable Resources. Chem. Rev. 2013, 113, 1499-1597. [CrossRef]

3. Teong, S.P.; Yi, G.S.; Zhang, Y.G. Hydroxymethylfurfural production from bioresources: Past, present and future. Green Chem. 2014, 16, 2015-2026. [CrossRef]

4. Carson, F.; Su, J.; Platero-Prats, A.E.; Wan, W.; Yun, Y.F.; Samain, L.; Zou, X.D. Framework Isomerism in Vanadium Metal-Organic Frameworks: MIL-88B(V) and MIL-101(V). Cryst. Growth Des. 2013, 13, 5036-5044. [CrossRef]

5. Roman-Leshkov, Y.; Moliner, M.; Labinger, J.A.; Davis, M.E. Mechanism of Glucose Isomerization Using a Solid Lewis Acid Catalyst in Water. Angew. Chem. Int. Edit. 2010, 49, 8954-8957. [CrossRef] [PubMed] 
6. Pidko, E.A.; Degirmenci, V.; van Santen, R.A.; Hensen, E.J.M. Glucose Activation by Transient $\mathrm{Cr}^{2+} \mathrm{Dimers}^{2}$ Angew. Chem. Int. Edit. 2010, 49, 2530-2534. [CrossRef] [PubMed]

7. Pagan-Torres, Y.J.; Wang, T.F.; Gallo, J.M.R.; Shanks, B.H.; Dumesic, J.A. Production of 5-Hydroxymethylfurfural from Glucose Using a Combination of Lewis and Bronsted Acid Catalysts in Water in a Biphasic Reactor with an Alkylphenol Solvent. ACS Catal. 2012, 2, 930-934. [CrossRef]

8. Choudhary, V.; Mushrif, S.H.; Ho, C.; Anderko, A.; Nikolakis, V.; Marinkovic, N.S.; Frenkel, A.I.; Sandler, S.I.; Vlachos, D.G. Insights into the Interplay of Lewis and Brønsted Acid Catalysts in Glucose and Fructose Conversion to 5-(Hydroxymethyl)furfural and Levulinic Acid in Aqueous Media. J. Am. Chem. Soc. 2013, 135, 3997-4006. [CrossRef]

9. Moliner, M.; Roman-Leshkov, Y.; Davis, M.E. Tin-containing zeolites are highly active catalysts for the isomerization of glucose in water. Proc. Nat. Acad. Sci. USA 2010, 107, 6164-6168. [CrossRef] [PubMed]

10. Herbst, A.; Janiak, C. Selective glucose conversion to 5-hydroxymethylfurfural (5-HMF) instead of levulinic acid with MIL-101Cr MOF-derivatives. New J. Chem. 2016, 40, 7958-7967. [CrossRef]

11. Nikolla, E.; Roman-Leshkov, Y.; Moliner, M.; Davis, M.E. “One-Pot” Synthesis of 5-(Hydroxymethyl)furfural from Carbohydrates using Tin-Beta Zeolite. ACS Catal. 2011, 1, 408-410. [CrossRef]

12. Degirmenci, V.; Hensen, E.J.M. Development of a Heterogeneous Catalyst for Lignocellulosic Biomass Conversion: Glucose Dehydration by Metal Chlorides in a Silica-Supported Ionic Liquid Layer. Environ. Prog. Sustainable Energy 2014, 33, 657-662. [CrossRef]

13. Furukawa, H.; Cordova, K.E.; O'Keeffe, M.; Yaghi, O.M. The Chemistry and Applications of Metal-Organic Frameworks. Science 2013, 341, 1230444. [CrossRef] [PubMed]

14. Seo, P.W.; Bhadra, B.N.; Ahmed, I.; Khan, N.A.; Jhung, S.H. Adsorptive Removal of Pharmaceuticals and Personal Care Products from Water with Functionalized Metal-organic Frameworks: Remarkable Adsorbents with Hydrogen-bonding Abilities. Sci. Rep. 2016, 6, 34462. [CrossRef] [PubMed]

15. Li, B.; Wen, H.M.; Zhou, W.; Chen, B.L. Porous Metal-Organic Frameworks for Gas Storage and Separation: What, How, and Why? J. Phys. Chem. Lett. 2014, 5, 3468-3479. [CrossRef] [PubMed]

16. Farrusseng, D.; Aguado, S.; Pinel, C. Metal-Organic Frameworks: Opportunities for Catalysis. Angew. Chem. Int. Edit. 2009, 48, 7502-7513. [CrossRef] [PubMed]

17. Corma, A.; Garcia, H.; Xamena, F. Engineering Metal Organic Frameworks for Heterogeneous Catalysis. Chem. Rev. 2010, 110, 4606-4655. [CrossRef]

18. Isaeva, V.I.; Kustov, L.M. The application of metal-organic frameworks in catalysis (Review). Petrol. Chem. 2010, 50, 167-180. [CrossRef]

19. Chughtai, A.H.; Ahmad, N.; Younus, H.A.; Laypkov, A.; Verpoort, F. Metal-organic frameworks: versatile heterogeneous catalysts for efficient catalytic organic transformations. Chem. Soc. Rev. 2015, 44, 6804-6849. [CrossRef]

20. Herbst, A.; Janiak, C. MOF catalysts in biomass upgrading towards value-added fine chemicals. CrystEngCommun 2017, 19, 4092-4117. [CrossRef]

21. Huang, Y.B.; Liang, J.; Wang, X.S.; Cao, R. Multifunctional metal-organic framework catalysts: synergistic catalysis and tandem reactions. Chem. Soc. Rev. 2017, 46, 126-157. [CrossRef] [PubMed]

22. Jiang, J.C.; Yaghi, O.M. Brønsted Acidity in Metal-Organic Frameworks. Chem. Rev. 2015, 115, 6966-6997. [CrossRef]

23. Goesten, M.G.; Juan-Alcaniz, J.; Ramos-Fernandez, E.V.; Gupta, K.; Stavitski, E.; van Bekkum, H.; Gascon, J.; Kapteijn, F. Sulfation of metal-organic frameworks: Opportunities for acid catalysis and proton conductivity. J. Catal. 2011, 281, 177-187. [CrossRef]

24. Juan-Alcaniz, J.; Gielisse, R.; Lago, A.B.; Ramos-Fernandez, E.V.; Serra-Crespo, P.; Devic, T.; Guillou, N.; Serre, C.; Kapteijn, F.; Gascon, J. Towards acid MOFs—catalytic performance of sulfonic acid functionalized architectures. Catal. Sci. Technol. 2013, 3, 2311-2318. [CrossRef]

25. Hu, Z.G.; Zhao, D. Metal-organic frameworks with Lewis acidity: Synthesis, characterization, and catalytic applications. CrystEngCommun 2017, 19, 4066-4081. [CrossRef]

26. Su, Y.; Chang, G.G.; Zhang, Z.G.; Xing, H.B.; Su, B.G.; Yang, Q.W.; Ren, Q.L.; Yang, Y.W.; Bao, Z.B. Catalytic dehydration of glucose to 5-hydroxymethylfurfural with a bifunctional metal-organic framework. AICHE J. 2016, 62, 4403-4417. [CrossRef] 
27. Chen, J.Z.; Li, K.G.; Chen, L.M.; Liu, R.L.; Huang, X.; Ye, D.Q. Conversion of fructose into 5-hydroxymethylfurfural catalyzed by recyclable sulfonic acid-functionalized metal-organic frameworks. Green Chem. 2014, 16, 2490-2499. [CrossRef]

28. Zhang, Y.M.; Degirmenci, V.; Li, C.; Hensen, E.J.M. Phosphotungstic Acid Encapsulated in Metal-Organic Framework as Catalysts for Carbohydrate Dehydration to 5-Hydroxymethylfurfural. ChemSusChem 2011, 4, 59-64. [CrossRef] [PubMed]

29. Guo, Q.; Ren, L.M.; Kumar, P.; Cybulskis, V.J.; Mkhoyan, K.A.; Davis, M.E.; Tsapatsis, M. A Chromium Hydroxide/MIL-101(Cr) MOF Composite Catalyst and Its Use for the Selective Isomerization of Glucose to Fructose. Angew. Chem. Int. Edit. 2018, 57, 4926-4930. [CrossRef] [PubMed]

30. Yabushita, M.; Li, P.; Islamoglu, T.; Kobayashi, H.; Fukuoka, A.; Farha, O.K.; Katz, A. Selective Metal-Organic Framework Catalysis of Glucose to 5-Hydroxymethylfurfural Using Phosphate-Modified NU-1000. Ind. Eng. Chem. Res. 2017, 56, 7141-7148. [CrossRef]

31. Oozeerally, R.; Burnett, D.L.; Chamberlain, T.W.; Walton, R.I.; Degirmenci, V. Exceptionally Efficient and Recylable Heterogeneous Metal-Organic Framework Catalyst for Glucose Isomerisation in Water. Chem CatChem 2018, 10, 706-709. [CrossRef]

32. De Mello, M.D.; Tsapatsis, M. Selective Glucose-to-Fructose Isomerization over Modified Zirconium UiO-66 in Alcohol Media. ChemCatChem 2018, 10, 2417-2423. [CrossRef]

33. Zhang, Y.L.; Jin, P.; Meng, M.J.; Gao, L.; Liu, M.; Yan, Y.S. Acid-Base Bifunctional Metal-Organic Frameworks: Green Synthesis and Application in One-Pot Glucose to 5-HMF Conversion. Nano 2018, 13. [CrossRef]

34. Gong, J.; Katz, M.J.; Kerton, F.M. Catalytic conversion of glucose to 5-hydroxymethylfurfural using zirconium-containing metal-organic frameworks using microwave heating. RSC Adv. 2018, 8, 31618-31627. [CrossRef]

35. Desidery, L.; Yusubov, M.S.; Zhuiykov, S.; Verpoort, F. Fully-sulfonated hydrated UiO-66 as efficient catalyst for ethyl levulinate production by esterification. Catal. Commun. 2018, 117, 33-37. [CrossRef]

36. Férey, G.; Mellot-Draznieks, C.; Serre, C.; Millange, F.; Dutour, J.; Surblé, S.; Margiolaki, I. A chromium terephthalate-based solid with unusually large pore volumes and surface area. Science 2005, 309, 2040-2042. [CrossRef]

37. Dayan, A.D.; Paine, A.J. Mechanisms of chromium toxicity, carcinogenicity and allergenicity: Review of the literature from 1985 to 2000. Hum. Exp. Toxicol. 2001, 20, 439-451. [CrossRef] [PubMed]

38. Ishihara, K.; Kubota, M.; Kurihara, H.; Yamamoto, H. Scandium trifluoromethanesulfonate as an extremely active Lewis acid catalyst in acylation of alcohols with acid anhydrides and mixed anhydrides. J. Org. Chem. 1996, 61, 4560-4567. [CrossRef]

39. Mowat, J.P.S.; Miller, S.R.; Slawin, A.M.Z.; Seymour, V.R.; Ashbrook, S.E.; Wright, P.A. Synthesis, characterisation and adsorption properties of microporous scandium carboxylates with rigid and flexible frameworks. Micropor. Mesopor. Mater. 2011, 142, 322-333. [CrossRef]

40. Mitchell, L.; Gonzalez-Santiago, B.; Mowat, J.P.S.; Gunn, M.E.; Williamson, P.; Acerbi, N.; Clarke, M.L.; Wright, P.A. Remarkable Lewis acid catalytic performance of the scandium trimesate metal organic framework MIL-100(Sc) for C-C and C=N bond-forming reactions. Catal. Sci. Technol. 2013, 3, 606-617. [CrossRef]

41. Mitchell, L.; Williamson, P.; Ehrlichova, B.; Anderson, A.E.; Seymour, V.R.; Ashbrook, S.E.; Acerbi, N.; Daniels, L.M.; Walton, R.I.; Clarke, M.L.; Wright, P.A. Mixed-Metal MIL-100(Sc,M) (M=Al, Cr, Fe) for Lewis Acid Catalysis and Tandem C-C Bond Formation and Alcohol Oxidation. Chem. Eur. J. 2014, 20, 17185-17197. [CrossRef] [PubMed]

42. Yang, L.; Zhao, T.; Boldog, I.; Janiak, C.; Yang, X.Y.; Li, Q.; Zhou, Y.J.; Xia, Y.; Lai, D.W.; Liu, Y.J. Benzoic acid as a selector-modulator in the synthesis of MIL-88B(Cr) and nano-MIL-101(Cr). Dalton Trans. 2019, 48, 989-996. [CrossRef] [PubMed]

43. Zhu, T.T.; Zhang, Z.M.; Chen, W.L.; Liu, Z.J.; Wang, E.B. Encapsulation of tungstophosphoric acid into harmless MIL-101(Fe) for effectively removing cationic dye from aqueous solution. RSC Adv. 2016, 6, 81622-81630. [CrossRef]

44. Bromberg, L.; Diao, Y.; Wu, H.M.; Speakman, S.A.; Hatton, T.A. Chromium(III) Terephthalate Metal Organic Framework (MIL-101): HF-Free Synthesis, Structure, Polyoxometalate Composites, and Catalytic Properties. Chem. Mater. 2012, 24, 1664-1675. [CrossRef] 
45. Wang, T.; Wang, J.; Zhang, C.L.; Yang, Z.; Dai, X.P.; Cheng, M.S.; Hou, X.H. Metal-organic framework MIL-101(Cr) as a sorbent of porous membrane-protected micro-solid-phase extraction for the analysis of six phthalate esters from drinking water: a combination of experimental and computational study. Analyst 2015, 140, 5308-5316. [CrossRef] [PubMed]

46. Montazerolghaem, M.; Aghamiri, S.F.; Tangestaninejad, S.; Talaie, M.R. A metal-organic framework MIL-101 doped with metal nanoparticles $\left(\mathrm{Ni} \& \mathrm{Cu}\right.$ ) and its effect on $\mathrm{CO}_{2}$ adsorption properties. RSC Adv. 2016, 6, 632-640.

47. Surblé, S.; Serre, C.; Mellot-Draznieks, C.; Millange, F.; Férey, G. A new isoreticular class of metal-organic-frameworks with the MIL-88 topology. Chem. Commun. 2006, 284-286. [CrossRef]

48. Bauer, S.; Serre, C.; Devic, T.; Horcajada, P.; Marrot, J.; Férey, G.; Stock, N. High-throughput assisted rationalization of the formation of metal organic frameworks in the iron(III) aminoterephthalate solvothermal system. Inorg. Chem. 2008, 47, 7568-7576. [CrossRef]

49. Tanasaro, T.; Adpakpang, K.; Ittisanronnachai, S.; Faungnawakij, K.; Butburee, T.; Wannapaiboon, S.; Ogawa, M.; Bureekaew, S. Control of Polymorphism of Metal-Organic Frameworks Using Mixed-Metal Approach. Cryst. Growth Des. 2018, 18, 16-21. [CrossRef]

50. Ma, M.Y.; Betard, A.; Weber, I.; Al-Hokbany, N.S.; Fischer, R.A.; Metzler-Nolte, N. Iron-Based Metal-Organic Frameworks MIL-88B and $\mathrm{NH}_{2}$-MIL-88B: High Quality Microwave Synthesis and Solvent-Induced Lattice "Breathing". Cryst. Growth Des. 2013, 13, 2286-2291. [CrossRef]

51. Serre, C.; Mellot-Draznieks, C.; Surblé, S.; Audebrand, N.; Filinchuk, Y.; Férey, G. Role of solvent-host interactions that lead to very large swelling of hybrid frameworks. Science 2007, 315, 1828-1831. [CrossRef]

52. Shannon, R.D. Revised effective ionic radii and systematic studies of interatomic distances in halides and chalcogenides. Acta Cryst. 1976, 32, 751-767. [CrossRef]

53. Gupta, R.P.; Sen, S.K. Calculation of multiplet structure of core $p$-vacancy levels. II. Phys. Rev. B 1975, 12, 15-19. [CrossRef]

54. Gota, S.; Guiot, E.; Henriot, M.; Gautier-Soyer, M. Atomic-oxygen-assisted MBE growth of a-Fe $\mathrm{O}_{3}$ on a- $\mathrm{Al}_{2} \mathrm{O}_{3}$ (0001): Metastable $\mathrm{FeO}(111)$-like phase at subnanometer thicknesses. Phys. Rev. B 1999, 60, 14387-14395. [CrossRef]

55. Biesinger, M.C.; Payne, B.P.; Grosvenor, A.P.; Lau, L.W.M.; Gerson, A.R.; Smart, R.S. Resolving surface chemical states in XPS analysis of first row transition metals, oxides and hydroxides: $\mathrm{Cr}, \mathrm{Mn}, \mathrm{Fe}, \mathrm{Co}$ and Ni. Appl. Surf. Sci. 2011, 257, 2717-2730. [CrossRef]

56. Jimenez-Cavero, P.; Lucas, I.; Anadon, A.; Ramos, R.; Niizeki, T.; Aguirre, M.H.; Algarabel, P.A.; Uchida, K.; Ibarra, M.R.; Saitoh, E.; Morellon, L. Spin Seebeck effect in insulating epitaxial gamma-Fe2O3 thin films. APL Mater. 2017, 5.

57. Jia, S.Y.; Xu, Z.W.; Zhang, Z.C. Catalytic conversion of glucose in dimethylsulfoxide/water binary mix with chromium trichloride: Role of water on the product distribution. Chem. Eng. J. 2014, 254, 333-339. [CrossRef]

58. Amarasekara, A.S.; Williams, L.D.; Ebede, C.C. Mechanism of the dehydration of D-fructose to 5-hydroxymethylfurfural in dimethyl sulfoxide at $150{ }^{\circ} \mathrm{C}$ : An NMR study. Carbohydr. Res. 2008, 343, 3021-3024. [CrossRef] [PubMed]

59. Swift, T.D.; Nguyen, H.; Anderko, A.; Nikolakis, V.; Vlachos, D.G. Tandem Lewis/Brønsted homogeneous acid catalysis: Conversion of glucose to 5-hydoxymethylfurfural in an aqueous chromium(III) chloride and hydrochloric acid solution. Green Chem. 2015, 17, 4725-4735. [CrossRef]

60. Li, K.; Du, M.M.; Ji, P.J. Multifunctional Tin-Based Heterogeneous Catalyst for Catalytic Conversion of Glucose to 5-Hydroxymethylfurfural. ACS Sust. Chem. Eng. 2018, 6, 5636-5644. [CrossRef]

61. Behera, G.C.; Parida, K.M. One-pot synthesis of 5-hydroxymethylfurfural: a significant biomass conversion over tin-promoted vanadium phosphate (Sn-VPO) catalyst. Catal. Sci. Technol. 2013, 3, 3278-3285. [CrossRef]

62. Ngee, E.L.S.; Gao, Y.J.; Chen, X.; Lee, T.M.; Hu, Z.G.; Zhao, D.; Yan, N. Sulfated Mesoporous Niobium Oxide Catalyzed 5-Hydroxymethylfurfural Formation from Sugars. Ind. Eng. Chem. Res. 2014, 53, 14225-14233. [CrossRef]

63. Yan, H.P.; Yang, Y.; Tong, D.M.; Xiang, X.; Hu, C.W. Catalytic conversion of glucose to 5-hydroxymethylfurfural over $\mathrm{SO}_{4}{ }^{2-} / \mathrm{ZrO}_{2}$ and $\mathrm{SO}_{4}{ }^{2-} / \mathrm{ZrO}_{2}-\mathrm{Al}_{2} \mathrm{O}_{3}$ solid acid catalysts. Catal. Commun. 2009, 10, 1558-1563. [CrossRef]

64. Jiang, H.X.; Zhou, J.L.; Wang, C.X.; Li, Y.H.; Chen, Y.F.; Zhang, M.H. Effect of Cosolvent and Temperature on the Structures and Properties of Cu-MOF-74 in Low-temperature $\mathrm{NH}_{3}$-SCR. Ind. Eng. Chem. Res. 2017, 56, 3542-3550. [CrossRef] 
65. Rahmani, E.; Rahmani, M. Alkylation of benzene over Fe-based metal organic frameworks (MOFs) at low temperature condition. Micropor. Mesopor. Mater. 2017, 249, 118-127. [CrossRef]

66. Vuong, G.T.; Pham, M.H.; Do, T.O. Synthesis and engineering porosity of a mixed metal $\mathrm{Fe}_{2} \mathrm{Ni} \mathrm{MIL-} 88 \mathrm{~B}$ metal-organic framework. Dalton Trans. 2013, 42, 550-557. [CrossRef] [PubMed]

67. Perles, J.; Iglesias, M.; Ruiz-Valero, C.; Snejko, N. Rare-earths as catalytic centres in organo-inorganic polymeric frameworks. J. Mater. Chem. 2004, 14, 2683-2689. [CrossRef]

68. Gandara, F.; Gomez-Lor, B.; Iglesias, M.; Snejko, N.; Gutierrez-Puebla, E.; Monge, A. A new scandium metal organic framework built up from octadecasil zeolitic cages as heterogeneous catalyst. Chem. Commun. 2009, 2393-2395. [CrossRef]

69. Larson, A.C.; Dreele, R.B.V. General Structure Analysis System (GSAS); Los Alamos National Laboratory Report 1994, LAUR 86-748; Los Alamos National Laboratory: Los Alamos, NM, USA, 1994.

70. Toby, B.H. EXPGUI, a graphical user interface for GSAS. J. Appl. Cryst. 2001, 34, 210-213. [CrossRef]

(C) 2019 by the authors. Licensee MDPI, Basel, Switzerland. This article is an open access article distributed under the terms and conditions of the Creative Commons Attribution (CC BY) license (http://creativecommons.org/licenses/by/4.0/). 